\title{
Performance Properties of Particleboard Panels Modified with Nanocellulose/Boric Acid
}

\author{
Mert Yildirim* and Zeki Candan
}

The physical and mechanical properties of particleboard panels were evaluated relative to various loading levels of nanocellulose $(\mathrm{NC})$ and boric acid (BA) in the urea-formaldehyde (UF) resin used for panel production. The results showed that NC and BA reinforcement substantially affected the performance properties of the particleboard panels. It was determined that using 3\% NC and 3\% BA in the panels afforded the best results relative to thickness swelling (TS), water absorption (WA), moisture content (MC), modulus of rupture (MOR), modulus of elasticity (MOE), and internal bonding strength (IB). It was concluded that the performance properties of the particleboard panels could be enhanced by adjusting the loading levels of NC and BA. The study also showed that it is possible to apply NC and BA as modifiers for the formaldehyde resin in the process of manufacturing particleboard panels. The NC and BA reinforcement techniques could be used to develop novel furniture components and interior design materials.

Keywords: Boric acid; Mechanical properties; Nanocellulose; Particleboard; Physical properties; Ureaformaldehyde resin

Contact information: Department of Forest Industrial Engineering, Istanbul University-Cerrahpasa, 34473, Istanbul, Turkey; *Corresponding author: mert.yildirim@ogr.iu.edu.tr

\section{INTRODUCTION}

In recent years, the use of lignocellulosic composites has grown because of its wide range of applications. The expanding use of lignocellulosic composites has been encouraged by a variety of factors, including the need for low-cost and high-performance composites, and the desire for sustainable industrial growth (Chen et al. 2020; Yildirim et al. 2020).

Particleboard, medium-density fiberboard (MDF), plywood, oriented strand board (OSB), laminated veneer lumber (LVL), etc., are some examples of the most common types of lignocellulosic composites. Among the various types of lignocellulosic composites, the particleboard panel is a main raw material used in furniture production. Particleboard is the biggest part of the market for lignocellulosic composites (Akbulut and Ayrilmis 2019). A particleboard panel is a wood-based composite consisting of lignocellulosic units of various sizes that are bonded together with a synthetic resin or binder under heat and pressure (Owodunni et al. 2020). It is commonly used to produce furniture, cabinets, shelving, countertops, and residential kitchens. It is also used for interior design and architectural applications.

The international market demand for particleboard is increasing day by day. Turkey is now the third-largest producer of particleboard in Europe after Russia and Germany, and it is ranked number four in the world after China, Russia, and Germany. Over the past 14 years, Turkey's lignocellulosic composites industry has achieved a remarkable average annual growth rate of about $10 \%$, which is almost twice the global average annual growth 
rate of $5.5 \%$ over the same time. As a result of high technology investments and high product quality achievements in the last 15 years, Turkey is now a net exporter of particleboard (Turkish Wood Based Panels Association 2019).

The lignocellulosic composite panel industry is a major consumer of amino resins such as urea-formaldehyde (UF) resin, phenol-formaldehyde (PF) resin, and melamineurea-formaldehyde (MUF) resin due to its cost efficiency and proven performance in the final products (Dunky 2004). UF resin is the most widely used and important type of amino plastic adhesive for the production of lignocellulosic composites due to its high reactivity, low cost, and easy processing (Pizzi 1994; Dunky 2003; Pizzi and Mittal 2003; Mantanis et al. 2017). However, UF resin has the main disadvantages of poor water resistance, easy aging, and brittleness (Pizzi 1994; Dunky 1998; Gao et al. 2020; Liu et al. 2020).

Many scientists have identified nanotechnology as the revolutionary technology of the $21^{\text {st }}$ century. Nanotechnology is enjoying impressive growth. The global market of nanotechnology is expected to exceed the US\$ 125 billion mark by 2024 (Liu and Xia 2020). Nanotechnology is defined as the understanding and control of matter at the nanoscale, at dimensions between 1 and 100 nanometers (Hulla et al. 2015). Nanotechnology offers many advantages for the forest products industry (Candan 2012; Candan and Akbulut 2013; Candan and Akbulut 2015). Studies on nanotechnology in the field of forest products are usually focused on the production of nanocellulose (NC) from wood-based lignocellulosic materials. Cellulose, the most ubiquitous and abundant natural biopolymer, has been subjected to intense research and development (Dufresne 2020; Tao and Xiu 2020). Nanocellulose consists of nanoscale cellulose-based materials derived from trees, annual plants, and agricultural residues generated by bacteria (Eskilson et al. 2020). The nanocellulose has unique properties including high-specific surface area, low thermal expansion coefficient, and outstanding reinforcing potential. Among many other sustainable nanomaterials, nanocellulose is drawing increasing interest for use in environmental applications due to its attractive properties.

Nanocellulose can be mainly classified into three main types; nanocrystalline cellulose (NCC), nanofibrillated cellulose (NFC), and bacterial nanocellulose (BNC). (Poyraz et al. 2017, 2018; Hochmanska and Janiszewska 2019). Especially, NFC particles are typically longer, more flexible, and are often branched, while NCC particles usually have short, rod-shaped particles. NFC is often used for reinforcing applications, while NCC is typically used for transparent applications. The benefits of using NC as reinforcements in adhesives for the manufacture of wood-based composite panels include the possibility of changing the properties of urea-formaldehyde, phenol-formaldehyde, and melamineUF-based adhesives, for the improvement in physical and mechanical properties of panels (Tozluoglu et al. 2018; Vineeth et al. 2019).

Many authors have evaluated the effects of NC-modified thermosetting adhesives on the performance properties of wood-based composite panels. Zhang et al. (2011) used UF resins reinforced with NC for producing plywood panels. It was stated that the internal bonding strength of the plywood panels increased as NC content increased up to $1.0 \%$. Urea-formaldehyde and melamine-UF were modified with $\mathrm{NC}$ and were used in particleboard and OSB production by Veigel et al. (2012). It was stated that thickness swelling values of the particleboard panels bonded with UF adhesive containing 1\% nanocellulose were lower than the panels bonded with unreinforced-UF adhesive. Kojima et al. (2013) investigated the binding effect of cellulose nanofibers in wood flour board as a reinforcement. The physical and mechanical properties of wood flour boards could be improved with the addition of NC due to the better binding effect between the NC and

Yildirim \& Candan (2021). "Particleboard with NC/BA," BioResources 16(1), 1875-1890. 1876 
wood flour particles. Candan and Akbulut (2014) used melamine-UF, where resins were reinforced with various nanomaterials for producing plywood panels. It was stated that it is possible to produce novel wood composites with improved performance properties using nanotechnology. Candan and Akbulut (2015) used UF resins reinforced with various nanoparticles for producing particleboard panels. It was stated that the mechanical performance of the particleboard panels was notably increased while the physical properties of the panel were negatively affected. Cui et al. (2015) studied the performance enhancement of the particleboard panels with cellulose nanofibers. Thickness swelling of the particleboard panels was not affected. Internal bonding strength increased with the addition of $2 \%$ of cellulose nanofibers. The modulus of elasticity (MOE) and modulus of rupture (MOR) of the panels were particularly increased. Mahrdt et al. (2016) investigated the effects of microfibrillated cellulose (MFC) addition on the distribution of ureaformaldehyde (UF) adhesive in particleboard. The authors declared that the addition of MFC to UF resin improves the mechanical bond strength of particleboard. Amini et al. (2017) studied the binder in the formulation of the particleboard panels with cellulose nanofibers. Physical properties, such as water absorption, thickness swelling, and mechanical properties, such as MOR, MOE, and internal bonding strength, were tested. The authors declared that particleboard panels met the industry requirements in terms of mechanical properties. Hansted et al. (2019) studied the physical properties of mediumdensity particleboard (MDP) panels after adding various proportions of nanocellulose to the UF-adhesive in MDP panel production. The authors declared that the addition of NC presented promising results from physical tests.

Boron is one of the most important industrial elements. As of 2019, Turkey had the largest reserves of boron globally. Turkey has an estimated 1.1 billion metric tons of boron in reserves (Eti Maden 2019). Boric acid is one of the most widely used boron compounds. Boron compounds have many advantages, such as retarding flame spread, low toxicity, low cost, high transparency, non-corrosiveness, and high thermal and biological resistance (Kartal 2009; Chai et al. 2012; Ayrilmis 2013; Wu and Xu 2014; Cavdar et al. 2015; Li et al. 2020). Terzi et al. (2017) declared that boron compounds available in various forms are likely to continue to be among the most encouraging biocides for wood protection for future manufacturers.

The aim of this study is to investigate the effects of NC and BA mixtures in addition to UF-resin on the physical and mechanical properties of particleboard panels.

\section{EXPERIMENTAL}

A mixture consisting of 45\% softwood (pine - Pinus spp.) and 55\% hardwood (oak - Quercus spp. and poplar - Populus spp.), UF resin with solid content of $50 \mathrm{wt} \%$, and liquid ammonium sulfate with solid content of $20 \mathrm{wt} \%$ were supplied by Kastamonu Integrated Wood Industry and Trade Inc., Istanbul, Turkey. Nanocellulose was string-like particles about $20 \mathrm{~nm}$ in diameter and 1 micron long. Nanocellulose used in this study was acquired from bleached wood pulp using the oxidation mediator 2,2,6,6-tetramethyl-1piperidine-1-oxyl (TEMPO method). The other material used was boric acid $\left(\mathrm{H}_{3} \mathrm{BO}_{3}\right)$. Its IUPAC name is trihydrooxidoboron. The experiment was conducted with seven different reinforced levels of NC/BA loadings, as shown in Table 1. 


\section{Manufacturing of Lignocellulosic Composites}

In this study, particleboard panels were manufactured as lignocellulosic composite materials. A resin reinforcement procedure was carried out in the Nanotechnology Laboratory at Istanbul University-Cerrahpasa (Istanbul, Turkey). Urea-formaldehyde resin was reinforced with $\mathrm{NC}$ at loading levels of $0 \%, 1 \%, 3 \%$, and BA at loading levels of $0 \%$, $1 \%, 3 \%$, and $5 \%$. Liquid ammonium sulfate with solid content of $20 \mathrm{wt} \%$ was added to the UF resin as a catalyst. Then, the UF resin was applied to the wood particles via a nozzle spray gun. Following the pre-pressing, the mats were put in the hydraulic hot press (Cemil Usta Company, Model: SSP 180, Istanbul Turkey). Experimental particleboard panels were pressed at $2.5 \mathrm{~N} / \mathrm{mm}^{2}$ pressure and $185^{\circ} \mathrm{C}$ for $5 \mathrm{~min}$. After the hot-pressing process, panels were conditioned in standard climate at $20{ }^{\circ} \mathrm{C} \pm 2{ }^{\circ} \mathrm{C}$ and $65 \% \pm 5 \%$ relative humidity to reach an equilibrium moisture content of approximately $12 \%$. The edges of the particleboard panels were trimmed to a final dimension of $500 \mathrm{~mm} \times 500 \mathrm{~mm} \times 10 \mathrm{~mm}$. For the physical and mechanical tests, three panels were produced from each particleboard type.

Table 1. Experimental Design of the Particleboard Panels

\begin{tabular}{|c|c|c|}
\hline Sample ID & Nanocellulose Loading Level (\%) & Boric Acid Loading Level (\%) \\
\hline 1 & 0 & 0 \\
\hline 2 & 1 & 3 \\
\hline 3 & 1 & 5 \\
\hline 4 & 1 & 1 \\
\hline 5 & 3 & 3 \\
\hline 6 & 3 & 5 \\
\hline 7 & 3 & \\
\hline
\end{tabular}

\section{Characterization of the Lignocellulosic Composites}

Physical properties of the particleboard panels

The density of the particleboard specimens was determined in accordance with EN 323 (1993). Then, 24-h thickness swelling (TS) of the particleboard specimens was determined in accordance with EN 317 (1993). The changes in the dimensional stability were measured following EN 318 (1993). Moisture content (MC) of the specimens was determined in accordance with EN 322 (1993). The initial weight and thickness of all test samples were measured. Specimens were immersed vertically in a water bath at $20 \pm 1{ }^{\circ} \mathrm{C}$. The TS and water absorption (WA) values were recorded after $2 \mathrm{~h}$ and $24 \mathrm{~h}$ of water immersion periods. The TS and WA values were calculated from the weight and thickness difference in relation to initial weight and thickness of each specimen.

\section{Mechanical properties of the particleboard panels}

Mechanical characterizations for the particleboard samples were carried out at the testing machine (IB600, IMAL, Modena, Italy) of Starwood Forest Products Inc., Bursa, Turkey. The modulus of rupture (MOR) and modulus of elasticity (MOE) of the 15 particleboard specimens was determined in accordance with the requirements of EN 310 (1993). Internal bonding (IB) strengths of the 10 particleboard specimens were determined for the 15 specimens in accordance with the requirements of EN 319 (1993). 


\section{Statistical Analysis}

In this work, the software (IBM SPSS Statistics 25, New York, NY, USA) was used for statistical analysis. The data obtained were evaluated by analysis of variance (two-way ANOVA) at $\mathrm{p}<0.05$. Significant differences between the mean values of reinforced and unreinforced groups were determined using Duncan's multiple range test.

\section{RESULTS AND DISCUSSION}

\section{Physical Properties of the Particleboard Panels}

Table 2 shows the density, TS, WA, and MC properties of particleboard panels.

Table 2. Average Physical Properties Values of Nanocellulose/Boric Acid Reinforced Particleboard Panels

\begin{tabular}{|c|c|c|c|c|c|c|c|}
\hline Sample ID & $\begin{array}{c}\text { Density } \\
\left(\mathrm{kg} / \mathrm{m}^{3}\right)\end{array}$ & \multicolumn{2}{|c|}{$\begin{array}{c}\text { Thickness } \\
\text { Swelling } \\
(\%)\end{array}$} & \multicolumn{2}{c|}{$\begin{array}{c}\text { Water } \\
\text { Absorption } \\
(\%)\end{array}$} & \multicolumn{2}{c|}{$\begin{array}{c}\text { Moisture } \\
\text { Content } \\
(\%)\end{array}$} \\
& & $2 \mathrm{~h}$ & $24 \mathrm{~h}$ & $2 \mathrm{~h}$ & $24 \mathrm{~h}$ & $2 \mathrm{~h}$ & $24 \mathrm{~h}$ \\
\hline 1 & 590 & 29.15 & 33.37 & 101.95 & 110.82 & 139.58 & 148.63 \\
& & $(3.75)$ & $(4.20)$ & $(16.70)$ & $(16.49)$ & $(30.89)$ & $(31.00)$ \\
\hline 2 & 520 & 22.28 & 24.55 & 149.40 & 158.44 & 211.86 & 221.02 \\
& & $(3.24)$ & $(3.44)$ & $(9.28)$ & $(9.17)$ & $(19.78)$ & $(20.20)$ \\
\hline 3 & 540 & 14.17 & 14.32 & 127.63 & 138.77 & 162.80 & 175.09 \\
& & $(2.41)$ & $(1.82)$ & $(9.87)$ & $(9.12)$ & $(12.44)$ & $(11.81)$ \\
\hline 4 & 610 & 22.32 & 23.98 & 106.36 & 116.51 & 160.25 & 164.81 \\
& & $(6.73)$ & $(6.08)$ & $(10.67)$ & $(13.60)$ & $(9.85)$ & $(14.21)$ \\
\hline 5 & 540 & 19.87 & 22.20 & 131.64 & 135.11 & 176.21 & 188.62 \\
& & $(4.19)$ & $(4.18)$ & $(10.55)$ & $(10.06)$ & $(15.46)$ & $(14.99)$ \\
\hline 6 & 580 & 16.83 & 19.53 & 108.57 & 118.62 & 137.11 & 148.52 \\
& & $(1.90)$ & $(2.09)$ & $(34.53)$ & $(35.98)$ & $(18.64)$ & $(18.20)$ \\
\hline 7 & 550 & 17.50 & 20.01 & 125.24 & 131.79 & 152.94 & 163.33 \\
& & $(1.63)$ & $(1.79)$ & $(4.68)$ & $(4.80)$ & $(5.57)$ & $(5.60)$ \\
\hline
\end{tabular}

\section{Density}

The density dispersion within lignocellulosic composites is one of the most significant panels quality properties which largely determines panel end uses. The average density values of the $\mathrm{NC}$ and BA reinforced particleboard panels ranged between 520 and $610 \mathrm{~kg} / \mathrm{m}^{3}$. The panel groups exhibited similar density values.

\section{Thickness Swelling}

The average TS values of NC/BA reinforced particleboard panels after 2 and $24 \mathrm{~h}$ water soaking periods are given in Table 2 . The results showed that the TS values of the $\mathrm{NC}$ and BA modified particleboard panels were significantly lower than those of unreinforced panels during 2 and $24 \mathrm{~h}$ water soaking periods. TS values after all water soaking periods of the particleboard panels decreased with increasing NC loading level, except the composites reinforced with $3 \% \mathrm{NC} / 3 \% \mathrm{BA}$. The $1 \% \mathrm{NC} / 3 \% \mathrm{BA}$ and $3 \% \mathrm{NC} / 3 \%$ BA reinforced panels had a maximum decrease in $24 \mathrm{~h}$ TS values with $57.0 \%$ and $41.4 \%$, compared with unmodified panels. 
A material can take on water without its thickness necessarily increasing. Since the holding of wood particles between each other increases, the thickness swelling decreases relatively. There may be decreases or no expected increases in some groups due to certain rates or unexpected reasons, such as aggregation.

Two-way ANOVA was performed to evaluate the influence of the $\mathrm{NC}$ and BA loading levels and the combined effect of the factors on TS properties of the particleboard panels after $24 \mathrm{~h}$.

The results indicated that the F-value for nanocellulose ratio was 19.105. Thus, there was a significant difference in thickness swelling quantity between panel groups at a $95 \%$ confidence level due to the value of 19.105 is greater than the value received from the related statistical tables. The F-value for the boric acid ratio was found to be 33.570. There was a significant difference in thickness swelling quantity between panel groups at a $95 \%$ confidence due to the value of 33.570 was greater than the value received from the related statistical tables. The F-value for NC/BA ratio was found to be 18.178. There was a significant difference in thickness swelling quantity between panel groups at a $95 \%$ confidence level due to the value of 18.178 is greater than the value received from the related statistical tables.

According to the results of Duncan's test conducted to investigate the effect of NC ratio on the TS values of particleboards, a significant difference was found between the panel groups at a 95\% confidence level. In this case, three homogeneous subgroups were formed. According to the results of Duncan's test conducted to investigate the effect of BA ratio on the TS values of particleboards, a significant difference was found between the panel groups at a $95 \%$ confidence level. In this case, three homogeneous subgroups were formed.

These results are supported by previous work from Hansted et al. (2019), who used $\mathrm{NC}$, reinforced UF-adhesives during the MDP panels production. The authors reported that the addition of NC had a positive effect on thickness swelling. Sun et al. (2019) reported that the shows a small positive effect of CNF addition on thickness swelling.

\section{Water Absorption}

The average WA values of NC/BA reinforced particleboard panels after $2 \mathrm{~h}$ and 24 $\mathrm{h}$ water soaking periods are given in Table 2 . The results revealed that WA values of the $\mathrm{NC}$ and BA modified particleboard panels were slightly higher than those of unreinforced particleboard panels, except that of the composites reinforced with $1 \% \mathrm{NC}$ and 5\% BA. The WA values after all water soaking periods of the particleboard panels decreased with increasing $\mathrm{NC}$ and BA loading levels, except the composites reinforced with $3 \% \mathrm{NC} / 5 \%$ BA. The highest WA values for all water soaking periods were determined in the particleboard panels reinforced with $1 \% \mathrm{NC}$ and $1 \% \mathrm{BA}$.

In general, $\mathrm{OH}$-groups are abundant in nanocellulose materials, making the material strongly hydrophilic. Due to the hydrophilic structure of nanocellulose/boric acid, water entered the structure, and WA values have been high compared to the unmodified group.

The addition of boric acid formed a strong interaction with nanocellulose, hence it decreased the water absorption remarkably. Boric acid could chemical that can interact with nanocellulose create cross-links within the wood particles, which results in a significant decrease in water absorption. Consequently, the water absorption of particleboard panels decreases as the increase of BA level. 
Two-way ANOVA was performed to evaluate the influence of the modifier loading levels, and the combined effect of the factors on water absorption properties of the particleboard panels after $24 \mathrm{~h}$.

The results indicated that the F-value for nanocellulose ratio was 21.933. There was a significant difference in WA between panel groups at a $95 \%$ confidence level due to the value of 21.933 being greater than the value received from the related statistical tables. The F-value for the boric acid ratio was 30.294. There was a significant difference WA between panel groups at a $95 \%$ confidence level due to the value of 30.294 was greater than the value received from the related statistical tables. The F-value for NC/BA ratio was found to be 6.275. There was a significant difference in WA between panel groups at a $95 \%$ confidence level due to the value of 6.275 being greater than the value received from the related statistical tables.

According to the results of Duncan's test conducted to investigate the effect of NC ratio on the WA values of particleboards, no significant difference between the control group panels $(\mathrm{NC}$ rate $=0 \%$ ) and the panel groups produced using $1 \% \mathrm{NC}$, at $95 \%$ confidence level. There was a significant difference between the other panel groups. In this case, two homogeneous subgroups were formed. According to the results of Duncan's test conducted to investigate the effect of BA ratio on the WA values of particleboards, no significant difference between the control group panels (BA rate $=0 \%$ ) and the panel groups produced using 3\% boric acid, at 95\% confidence level. There was a significant difference between the other panel groups. In this case, three homogeneous subgroups were formed.

These results are supported by previous studies of Kartal et al. (2007), who evaluated the water absorption of wood specimens treated with boron compounds. The authors reported that the modified wood caused increased water absorption due to the hygroscopicity of boric acid. Pawlak and Boruszewski (2018), who used micro-fibrillated cellulose, reinforced UF-adhesives during the low-density particleboard production. The authors reported that the addition of micro-fibrillated cellulose had a positive effect on the water resistance.

\section{Moisture Content}

The average MC values of NC/BA reinforced particleboard panels after 2 and $24 \mathrm{~h}$ water soaking periods are given in Table 2. The findings indicated that the NC/BA reinforced particleboard panels had significantly higher $\mathrm{MC}$ values than those of unreinforced panels. The MC values after all water soaking periods of the particleboard panels decreased with increasing $\mathrm{NC}$ and $\mathrm{BA}$ loading levels, except for the composites reinforced with 3\% NC/5\% BA. It was determined that using 3\% $\mathrm{NC}$ and 3\% $\mathrm{BA}$ in the particleboard panels resulted in the lowest MC values. The higher moisture content of panels with higher levels of NC can be attributed to the loss of bonds between the wood particles during water soaking.

Two-way ANOVA indicated that the NC and BA loading levels and their combined factors significantly affected the MC values of the particleboard panels after $24 \mathrm{~h}$ water soaking periods.

The results indicated that the F-value for nanocellulose ratio was 6.797. There was a significant difference in moisture content quantity between panel groups at a $95 \%$ confidence level due to the value of 6.797 was greater than the value received from the related statistical tables. The F-value for the boric acid ratio was 50.705. There was a significant difference in moisture content quantity between panel groups at a $95 \%$ 
confidence level due to the value of 50.705 is greater than the value received from the related statistical tables. The F-value for NC/BA ratio was 10.059 . There was a significant difference in moisture content quantity between panel groups at a $95 \%$ confidence level due to the value of 10.059 was greater than the value received from the related statistical tables.

According to the results of Duncan's test conducted to investigate the effect of NC ratio on the $\mathrm{MC}$ values of particleboards, no significant difference was found between the panel groups at a 95\% confidence level. In this case, one homogeneous subgroup was formed. According to the results of Duncan's test conducted to investigate the effect of BA ratio on the MC values of particleboards, a significant difference was found between the panel groups at a $95 \%$ confidence level. In this case, two homogeneous subgroups were formed.

Gabr et al. (2013) reported that nanocellulose had a negative effect on moisture absorption. Hansted et al. (2019) reported that the addition of NC resulted in no significant statistical difference in the density and MC of the MDP panels.

\section{Mechanical Properties of the Particleboard Panels}

Table 3 shows the average values of the MOR, MOE, and IB strengths.

Table 3. Average Mechanical Properties Values of Nanocellulose/Boric Acid Reinforced Particleboard Panels

\begin{tabular}{|c|c|c|c|}
\hline Sample ID & $\begin{array}{c}\text { Modulus of Rupture } \\
\left(\mathrm{N} / \mathrm{mm}^{2}\right)\end{array}$ & $\begin{array}{c}\text { Modulus of Elasticity } \\
\left(\mathrm{N} / \mathrm{mm}^{2}\right)\end{array}$ & $\begin{array}{c}\text { Internal Bonding } \\
\left(\mathrm{N} / \mathrm{mm}^{2}\right)\end{array}$ \\
\hline 1 & $2.95(0.37)$ & $516.52(87.77)$ & $0.19(0.05)$ \\
\hline 2 & $2.30(0.72)$ & $322.68(110.52)$ & $0.14(0.03)$ \\
\hline 3 & $3.05(0.75)$ & $565.92(101.82)$ & $0.25(0.06)$ \\
\hline 4 & $2.92(0.47)$ & $526.92(104.64)$ & $0.13(0.05)$ \\
\hline 5 & $2.72(0.98)$ & $400.98(135.16)$ & $0.18(0.03)$ \\
\hline 6 & $4.43(0.69)$ & $666.88(61.73)$ & $0.39(0.10)$ \\
\hline 7 & $3.70(0.56)$ & $544.92(73.26)$ & $0.31(0.06)$ \\
\hline \multicolumn{2}{|r|}{} \\
\hline
\end{tabular}

\section{Modulus of Rupture}

The modulus of rupture measures the ultimate load-carrying capacity in lignocellulosic composites. The average MOR results of reinforced particleboard panels are given in Table 2. It is apparent that the NC reinforcement affected the MOR performance of the particleboard panels. While the lowest MOR value of panels which were produced at $1 \% \mathrm{NC} / 1 \% \mathrm{BA}$ ratio was calculated as $2.30 \mathrm{~N} / \mathrm{mm}^{2}$, the highest value was obtained in $3 \% \mathrm{NC} / 3 \% \mathrm{BA}$, calculated as $4.43 \mathrm{~N} / \mathrm{mm}^{2}$ with an improvement of approximately $50.1 \%$. The MOR values of the reinforced panels increased significantly with increasing the NC/BA loading levels from $1 \%$ to $3 \%$.

Two-way ANOVA results indicated that the MOR values of the particleboard panels were significantly affected. The results indicated that the F-value for nanocellulose ratio was 12.510. There was a significant difference in MOR between panel groups at a $95 \%$ confidence level due to the value of 12.510 being greater than the value received from the related statistical tables. The F-value for the boric acid ratio was 27.037. There was a significant difference MOR between panel groups at a 95\% confidence level due to the 
value of 27.037 was greater than the value received from the related statistical tables. The F-value for NC/BA ratio was 3.993. There was a significant difference in MOE between panel groups at a $95 \%$ confidence level due to the value of 3.993 is greater than the value received from the related statistical tables.

According to the results of Duncan's test conducted to investigate the effect of NC ratio on the MOR values of particleboards, a significant difference was found between the panel groups at a 95\% confidence level. In this case, two homogeneous subgroups were formed. According to the results of Duncan's test conducted to investigate the effect of the $\mathrm{BA}$ ratio on the MOR values of the particleboards, no significant difference between the control group panels $(\mathrm{BA}$ ratio $=0 \%$ ) and the panel groups produced using $5 \% \mathrm{BA}$, at $95 \%$ confidence level. There was a significant difference between the other panel groups. In this case, three homogeneous subgroups were formed.

Veigel et al. (2012) concluded that the particleboard panels bonded with an adhesive containing $1 \% \mathrm{NC}$ had higher MOR values than the particleboard panels with neat UF-adhesive. Rojo et al. (2015) indicated that the cellulose loading level significantly affected the mechanical properties of the composites. It was reported that low cellulose loading levels, such as $1 \%$, decreased the mechanical properties of the composites. Leng et al. (2017) studied wet-formed particleboard bonded with cellulose nanofibrils (CNF). The authors reported that the $\mathrm{CNF}$ addition ratio had the most significant effect on the MOR. Claramunt et al. (2019) concluded that the addition of 0.1 to $0.2 \mathrm{wt} \%$ of either type of nanocellulose led to an increase in the MOR values. Sun et al. (2019) declared that the CNF impressively improved the modulus of rupture at low addition rates.

\section{Modulus of Elasticity}

The modulus of elasticity measures the resistance to bending and reveals the stiffness of the lignocellulosic composites. The average MOE results of reinforced particleboard panels are given in Table 2. The MOE values of the NC and BA reinforced particleboard panels were higher than those of the unreinforced particleboard panels, except that of the panels reinforced with $1 \% \mathrm{NC} / 1 \% \mathrm{BA}, 3 \% \mathrm{NC} / 1 \% \mathrm{BA}$. The MOE values of the reinforced panels increased significantly with increasing the NC/BA loading levels from $1 \%$ to $3 \%$. The highest MOE value was obtained in 3\% $\mathrm{NC}$ and 3\% BA reinforced particleboard panels with an improvement of approximately $29 \%$.

Two-way ANOVA indicated that the NC and BA loading levels and combined effect of the two factors significantly affected the MOE values of the particleboard panels. The F-value for nanocellulose ratio was 28.875. There was a significant difference in MOE between panel groups at a $95 \%$ confidence level due to the value of 28.875 being greater than the value received from the related statistical tables. The F-value for the boric acid ratio was 52.547. There was a significant difference in MOE between panel groups at a $95 \%$ confidence level due to the value of 52.547 was greater than the value received from the related statistical tables. The F-value for NC/BA ratio was found to be 1.399. There was no significant difference in MOE between panel groups at a 95\% confidence level due to the value of 1.399 being smaller than the value received from the related statistical tables.

According to the results of Duncan's test conducted to investigate the effect of NC ratio on the MOE values of particleboards, a significant difference was found between the panel groups at $95 \%$ confidence level. In this case, two homogeneous subgroups were formed. According to the results of Duncan's test conducted to investigate the effect of BA ratio on the MOE values of particleboards, no significant difference between the control group panels $(\mathrm{BA}$ rate $=0 \%$ ) and the panel groups produced using $5 \% \mathrm{BA}$, at $95 \%$ 
confidence level. There was a significant difference between the other panel groups. In this case, three homogeneous subgroups were formed.

The results obtained are supported by the previous work of Nakagaito and Yano (2008), which revealed that there was no linear relationship between Young's modulus of the composites and cellulose fiber content. Cui et al. (2015) concluded that the particleboard panels containing $\mathrm{CNF}$ of the resins were also notably increased. Efhamisisi et al. (2016) reported the addition of BA increased the modulus of elasticity of the adhesive. Claramunt et al. (2019) concluded that the addition of nanocellulose significantly improving MOE values. Sun et al. (2019) declared that the CNF increased the modulus of elasticity, optimally at $2.5 \%$ addition. Kawalerczyk et al. (2020) concluded that NC had a positive effect on MOE.

\section{Internal Bonding Strength}

IB is one of the most significant tests, and it was used as a determiner of the inner bond quality of panels. The average IB results of reinforced particleboard panels are given in Table 2. It displays that the NC/BA reinforcement significantly affected the IB performance of the particleboard panels. It was found that the IB values of the panels ranged between 0.13 and $0.39 \mathrm{~N} / \mathrm{mm}^{2}$. When the nanocellulose ratio was increased from $1 \%$ to $3 \%$, the internal bond increased from 0.13 to $0.31 \mathrm{~N} / \mathrm{mm}^{2}$. The IB values of the reinforced panels increased significantly with increasing the NC/BA loading level from $1 \%$ to $3 \%$. The highest IB value was obtained in $3 \% \mathrm{NC}$ and $3 \% \mathrm{BA}$ reinforced particleboard panels, with an improvement of $100 \%$. As can be seen from the IB results or other mechanical performance, generally nanocellulose reinforcement affected positively the final panels' performance. Nanocellulose enhances the internal bonding strength properties of the adhesive. Thanks to the high specific surface area and fiber structure on a nanoscale, nanocellulose creates strong bonds. Therefore, mechanical strength values were increasing with the addition of NC.

Two-way ANOVA showed that the NC and BA loading levels and their combined effect significantly affected the IB strength values of the particleboard panels. The results indicated that the F-value for nanocellulose ratio was 31.034. There was a significant difference in IB strength between panel groups at a 95\% confidence level due to the value of 31.034 was greater than the value received from the related statistical tables. The Fvalue for the boric acid ratio was 73.618. There was a significant difference in IB strength between panel groups at a $95 \%$ confidence level due to the value of 73.618 was greater than the value received from the related statistical tables. The F-value for NC/BA ratio was 12.623. There was no significant difference in IB strength between panel groups at a $95 \%$ confidence level due to the value of 12.623 was smaller than the value received from the related statistical tables.

According to the results of Duncan's test conducted to investigate the effect of NC ratio on the IB strength values of particleboards, a significant difference was found between the panel groups at a 95\% confidence level. In this case, three homogeneous subgroups were formed. According to the results of Duncan's test conducted to investigate the effect of BA ratio on the IB strength values of particleboards, a significant difference was found between the panel groups at a $95 \%$ confidence level. In this case, four homogeneous subgroups were formed.

These results are supported by the previous report of Zhang et al. (2011), who examined bonding quality properties of the UF bonded plywood panels. It was indicated that the bonding quality of the composite panels increased with nanocellulose because of

Yildirim \& Candan (2021). "Particleboard with NC/BA," BioResources 16(1), 1875-1890. 1884 
interactions between nanocellulose and UF adhesive. Parallel results were also found by Cui et al. (2015). They investigated the effect of CNF on the performance properties of particleboard panels. Internal bonding strength increased with the addition of $2 \%$ of NC. Efhamisisi et al. (2016) reported the BA in the glue line improved the bonding quality of the panels. Hunt et al. (2017) investigated the effects of IB strength properties of NCcontaining particleboards. The authors reported that the increased NC ratio could improve IB properties for the high-density particleboard. Kasmani and Samariha (2019) declared that the addition of NFC at $8 \%$ increased the tensile strength compared to $0 \%$ NFC (10.9\%).

\section{CONCLUSIONS}

1. The results obtained in this study revealed that nanocellulose (NC) and boric acid (BA) reinforcement significantly affected the physical and mechanical performance properties of the particleboard panels.

2. The use of NC/BA reinforcement technique caused an increase of water absorption (WA) and moisture content (MC), while reducing the thickness swelling (TS) of the particleboard.

3. Modulus of rupture (MOR), modulus of elasticity (MOE), and internal bonding (IB) properties of particleboard panels produced with an optimum amount of NC increased greatly in comparison to the unreinforced samples. If the particleboard panels are to be used for mechanical strength applications, NC and BA loading level should not be less than $3 \%$.

4. It was concluded that the physical and mechanical performance properties of the lignocellulosic composites could be enhanced by altering the $\mathrm{NC}$ and BA loading levels.

\section{ACKNOWLEDGMENTS}

The authors would like to thank Istanbul University-Cerrahpasa Research Fund for its financial support in this study (Project No. 31076). Additionally, the support from Project Nos. 4806, 19515, 31014, 43150, and 49525 is greatly acknowledged. The authors thank Kastamonu Integrated Wood Industry and Trade Inc., Gebze, Turkey for providing raw materials, and Starwood Forest Products Inc., Bursa, Turkey for testing facilities. The support from Turkish Academy of Sciences is also appreciated.

\section{REFERENCES CITED}

Akbulut, T., Ayrilmis, N. (2019). "Some advantages of three-layer medium-density fibreboard as compared to the traditional single-layer one," Journal of Wood Science 65, Article ID: 46. DOI: 10.1186/s10086-019-1822-4

Amini, E., Tajvidi, M., Gardner, D. J., and Bousfield, D. W. (2017). "Utilization of cellulose nanofibrils as a binder for particleboard manufacture," BioResources 12(2), 4093-4110. DOI: 10.15376/biores.12.2.4093-4110 
Ayrilmis, N. (2013). "Combined effects of boron and compatibilizer on dimensional stability and mechanical properties of wood/HDPE composites," Composites Part B: Engineering 44(1), 745-749. DOI: 10.1016/j.compositesb.2012.04.002

Candan, Z. (2012). Nanoparticles Use in Manufacture of Wood-based Sandwich Panels and Laminate Flooring and its Effects on Technological Properties, Ph.D. Dissertation, Istanbul University, Istanbul, Turkey.

Candan, Z., and Akbulut, T. (2013). "Developing environmentally friendly wood composite panels by nanotechnology," BioResources 8(3), 3590-3598. DOI: 10.15376/biores.8.3.3590-3598

Candan, Z., and Akbulut, T. (2014). "Nano-engineered plywood panels: Performance properties," Composites Part B: Engineering 64, 155-161. DOI: 10.1016/j.compositesb.2014.04.021

Candan, Z., and Akbulut, T. (2015). "Physical and mechanical properties of nanoreinforced particleboard composites," Maderas. Ciencia y Tecnología 17(2), 319-334. DOI: $10.4067 / \mathrm{s} 0718-221 \times 2015005000030$

Candan, Z., Gardner, D. J., and Shaler, S. M. (2016). "Dynamic mechanical thermal analysis (DMTA) of cellulose nanofibril/nanoclay/pMDI nanocomposites," Composites Part B: Engineering 90, 126-132. DOI:

10.1016/j.compositesb.2015.12.016

Cavdar, A. D., Mengeloglu, F., and Karakus, K. (2015). "Effect of boric acid and borax on mechanical, fire and thermal properties of wood flour filled high density polyethylene composites," Measurement 60, 6-12. DOI: 10.1016/j.measurement.2014.09.078

Chai, Y. B., Liu, J. L., and Zhen, X. (2012). "Dimensional stability, mechanical properties and fire resistance of MUF-boron treated wood," Advanced Materials Research 341-342, 80-84. DOI: 10.4028/www.scientific.net/AMR.341-342.80

Chen, C., Kuang, Y., Zhu, S., Burgert, I., Keplinger, T., Gong, A., Li, T., Berglund, L., Eichhom, S., and Hu, L. (2020). "Structure-property-function relationships of natural and engineered wood," Nature Reviews Materials 5, 642-666. DOI: 10.1038/s41578020-0195-z

Claramunt, J., Ventura, H., Toledo Filho. R. D, and Ardanuy, M. (2019). "Effect of nanocelluloses on the microstructure and mechanical performance of CAC cementitious matrices," Cement and Concrete Research 119, 64-76. DOI: 10.1016/j.cemconres.2019.02.006.

Cui, J., Lu, X., Zhou, X., Chrusciel, L., Deng, Y., Zhou, H., Zhu, S., and Brosse, N. (2015). "Enhancement of mechanical strength of particleboard using environmentally friendly pine (Pinus pinaster L.) tannin adhesives with cellulose nanofibers," Annals of Forest Science 72, 27-32. DOI: 10.1007/s13595-014-0392-2

Dufresne, A. (2020). "Preparation and properties of cellulose nanomaterials," Paper and Biomaterials 5(3), 1-13. DOI: 10.12103/j.issn.2096-2355.2020.03.001

Dunky, M. (1998). "Urea-formaldehyde (UF) adhesive resins for wood," International Journal of Adhesion and Adhesives 18(2), 95-107. DOI: 10.1016/S01437496(97)00054-7.

Dunky, M. (2003). Adhesives in the wood industry, Marcel Dekker Inc., New York, NY, USA.

Dunky, M. (2004). "Adhesives based on formaldehyde condensation resins," Macromolecular Symposia 217(1), 417-430. DOI: 10.1002/masy.200451338 
EN 310 (1993). "Wood-based panels - Determination of modulus of elasticity in bending and of bending strength," European Committee for Standardization, Brussels, Belgium.

EN 317 (1993). "Particleboards and fiberboards, determination of swelling in thickness after immersion," European Committee for Standardization, Brussels, Belgium.

EN 318 (1993). "Wood based panels - Determination of dimensional changes associated with changes in relative humidity," European Committee for Standardization, Brussels, Belgium.

EN 319 (1993). "Particleboards and fibreboards - Determination of tensile strength perpendicular to the plane of the board," European Committee for Standardization, Brussels, Belgium.

EN 322 (1993). "Wood-based panels - Determination of moisture content," European Committee for Standardization, Brussels, Belgium.

EN 323 (1993). "Wood-based panels - Determination of density," European Committee for Standardization, Brussels, Belgium.

Efhamisisi, D., Thevenon, M. F., Hamzeh, Y., Karimi, A. N., Pizzi, A., and Pourtahmasi, K. (2016). "Induced tannin adhesive by boric acid addition and its effect on bonding quality and biological performance of poplar plywood," ACS Sustainable Chemistry \& Engineering 4(5), 2734-2740. DOI: 10.1021/acssuschemeng.6b00230

Eskilson, O., Shahjamali, M. M., Sivlér, P., Skog, M., Aronsson, C., Nyberg, N., Martinsson, E., Selegård, R., and Aili, D. (2020). "Self-assembly of mechanoplasmonic bacterial cellulose-metal nanoparticle composites," Advanced Functional Materials 30(40), Article ID 2004766. DOI: 10.1002/adfm.202004766

Eti Maden. (2019). “Annual Report,” Ankara, Turkey.

Gabr, M. H., Phong, N. T., Abdelkareem, M. A, Okubo, K., Uzawa, K., Kimpara, I., and Fujii, T. (2013). "Mechanical, thermal, and moisture absorption properties of nanoclay reinforced nano-cellulose biocomposites," Cellulose 20, 819-826.

DOI:10.1007/s10570-013-9876-8

Gao, S., Liu, Y., Wang, C., Chu, F., Xu, F., and Zhang, D. (2020). "Synthesis of ligninbased polyacid catalyst and its utilization to improve water resistance of ureaformaldehyde resins," Polymers 12(1), 175. DOI: 10.3390/polym12010175.

Hansted, F. A. S., Hansted, A. L. S., Padilha, E. R. D., Caraschi, J. C., Goveia, D., and Inácio de Campos, C. (2019). "The use of nanocellulose in the production of medium density particleboard panels and the modification of its physical properties," BioResources 14(3), 5071-5079. DOI: 10.15376/biores.14.3.5071-5079

Hochmanska, P., and Janiszewska, D. (2019). "Stability and rheological behavior of nanocellulose-modified UF resin compositions," BioResources 14(1), 1850-1866. DOI: 10.15376/biores.14.1.1850-1866

Hulla, J. E., Sahu, S. C., and Hayes, A. W. (2015). "Nanotechnology: History and future," Human and Experimental Toxicology 34(12), 1318-1321. DOI:10.1177/0960327115603588.

Hunt, J. F., Leng, W., and Tajvidi, M. (2017). "Vertical density profile and internal bond strength of wet-formed particleboard bonded with cellulose nanofibrils," Wood and Fiber Science 49(4), 1-11.

Kartal, S. N., Hwang, W. J., and Imamura, Y. (2007). "Water absorption of boron-treated and heat-modified wood," Journal of Wood Science 53(5), 454-457. DOI:

10.1007/s10086-007-0877-9 
Kartal, S. N. (2009). "Boron-based wood preservatives and their use," in: Handbook on Borates: Chemistry, Production and Applications, M. P. Chung (ed.), Nova Science Publishers, Inc., Hauppauge, NY, USA, pp. 329-348.

Kasmani, J. E., and Samariha, A. (2019). "Effect of nano-cellulose on the improvement of the properties of paper newspaper produced from chemi-mechanical pulping," BioResources 14(4), 8935-8949.

Kawalerczyk, J., Dziurka, D., Mirski, R., Siuda, J., and Szentner, K. (2020). “The effect of nanocellulose addition to phenol-formaldehyde adhesive in water-resistant plywood manufacturing," BioResources 15(3), 5388-5401. DOI: 10.15376/biores.15.3.5388-5401

Kojima, Y., Jun, M., Akiko, I., Shigehiko, S., Hirokazu, I., Rie, M., and Masaki, O. (2013). "Binding effect of cellulose nanofibers in wood flour board," Journal of Wood Science 59, 396-401. DOI: 10.1007/s10086-013-1348-0

Leng, W. Q., Hunt, J. F., and Tajvidi, M. (2017). "Effects of density, cellulose nanofibrils addition ratio, pressing method, and particle size on the bending properties of wetformed particleboard," BioResources 12(3), 4986-5000. DOI: 10.15376/biores. 12.3.4986-5000

Li, H., Ma, X., Gu, Z., Wang, X., Li, J., Jiang, J., Fei, B., and Yang, Z. (2020). "Pyrolysis and combustion characteristics of boric acid and borax treated decorative bamboo filaments," BioResources 15(4), 8146-8160. DOI: 10.15376/biores.15.4.8146-8160

Liu, K., Su, C., Ma, W., Li, H., Zeng, Z., and Li, L. (2020). "Free formaldehyde reduction in urea-formaldehyde resin adhesive: Modifier addition effect and physicochemical property characterization," BioResources 15(2), 2339-2355. DOI: 10.15376/biores.15.2.2339-2355

Liu, S., and Xia, T. (2020). "Continued efforts on nanomaterial-environmental health and safety is critical to maintain sustainable growth of nanoindustry," Small 16(21), 1-9. DOI: $10.1002 / \mathrm{smll} .202000603$

Mahrdt, E., Pinkl, S., Schmidberger, C., van Herwijnen, H. W. G., Veigel, S., and GindlAltmutter, W. (2016). "Effect of addition of microfibrillated cellulose to ureaformaldehyde on selected adhesive characteristics and distribution in particle board," Cellulose 23(1), 571-580. DOI: 10.1007/s10570-015-0818-5

Mantanis, G. I., Athanassiadou, E. T., Barbu, M. C., and Wijnendaele, K. (2017). "Adhesive systems used in the European particleboard, MDF and OSB industries," Wood Material Science and Engineering 13(2), 104-116. DOI: 10.1080/17480272.2017.1396622.

Nakagaito, A. N., and Yano, H. (2008). "The effect of fiber content on the mechanical and thermal expansion properties of biocomposites based on microfibrillated cellulose," Cellulose 15, 555-559. DOI: 10.1007/s10570-008-9212-x

Owodunni, A. A., Lamaming, J., Hashim, R., Abdulwahab Taiwo, O. F., Hussin, M. H., Mohamad Kassim, M. H., Bustami, Y., Sulaiman, O., Mohamad Amini, M. H., and Hiziroglu, S. (2020). "Properties of green particleboard manufactured from coconut fiber using a potato starch based adhesive," BioResources 15(2), 2279-2292. DOI: 10.15376/biores.15.2.2279-2292

Pawlak, D., and Boruszewski, P. (2018). "Influence of addition of microfibrillated cellulose (MFC) on selected properties of low-density particleboard," Annals of Warsaw University of Life Sciences-SGGW Forestry and Wood Technology 102, 139148. 
Pizzi, A. (1994). Advanced Wood Adhesives Technology, Marcel Dekker Inc., New York, NY, USA.

Pizzi, A., and Mittal K. L. (2003). Handbook of Adhesive Technology, Marcel Dekker Inc., New York, NY, USA.

Poyraz, B., Tozluoglu, A., Candan, Z., and Demir, A. (2017). "Matrix impact on the mechanical, thermal and electrical properties of microfluidized nanofibrillated cellulose composites," Journal of Polymer Engineering 37(9), 921-931. DOI: 10.1515/polyeng-2017-0022

Poyraz, B., Tozluoglu, A., Candan, Z., Demir, A., and Yavuz, M. (2017). "Influence of PVA and silica on chemical, thermo-mechanical and electrical properties of celluclast-treated nanofibrillated cellulose composites," International Journal of Biological Macromolecules 104(Part A), 384-392. DOI: 10.1016/j.ijbiomac.2017.06.018

Poyraz, B., Tozluoglu, A., Candan, Z., Demir, A., Yavuz, M., Buyuksari, U., Unal, H. I., Fidan, H., and Saka, R. C. (2018). "TEMPO-treated CNF composites: Pulp and matrix effect," Fibers and Polymers 19(1), 195-204. DOI:10.1007/s12221-018-7673-y

Rojo, E., Alonso, M. V., Oliet, M. G., Saz-Orozco, B. D., and Rodríguez, F. M. (2015). "Effect of fiber loading on the properties of treated cellulose fiber-reinforced phenolic composites," Composites Part B: Engineering 68, 185-192. DOI: 10.1016/j.compositesb.2014.08.047

Sun, W., Tajvidi, M., Hunt, C. G. McIntyre, G., and Gardner, D. J. (2019). "Fully biobased hybrid composites made of wood, fungal mycelium and cellulose nanofibrils," Scientific Reports 9, 3766. DOI:10.1038/s41598-019-40442-8

Tao, J., and Xu, Y. (2020). "Cellulose nanocrystals-based chiroptical materials," Paper and Biomaterials, 5(3), 14-30. DOI: 10.12103/j.issn.2096-2355.2020.03.002

Terzi, E., Kartal, S. N., Gerardin, P., Ibanez, C. M., and Yoshimura, T. (2017). "Biological performance of particleboard incorporated with boron minerals," Journal of Forestry Research 28, 195-203. DOI: 10.1007/s11676-016-0288-0

Tozluoglu, A., Poyraz, B., and Candan, Z. (2018). "Examining the efficiency of mechanic/enzymatic pretreatments in micro/nanofibrillated cellulose production," Maderas. Ciencia y Tecnología 20(1), 67-84. DOI: 10.4067/S0718221X2018005001601

Tozluoglu, A., Poyraz, B., McDonald, A. G., and Candan, Z. (2018). “Developing nanocellulose-based biofilms from kraft and $\mathrm{NaBH}_{4}$-modified kraft pulp," Cellulose Chemistry and Technology 52(3-4), 223-237.

Turkish Wood Based Panels Association. (2019). "Wood based panels production capacity reports," Istanbul, Turkey.

Veigel, S., Rathke, J., Weigl, M., and Gindl-Altmutter, W. (2012). "Particle board and oriented strand board prepared with nanocellulose-reinforced adhesive," Journal of Nanomaterials (2012)1, Article ID 158503. DOI: 10.1155/2012/158503

Vineeth, S. K., Gadhave, R. V., and Gadekar, P. T. (2019). "Nanocellulose applications in wood adhesives-Review," Open Journal of Polymer Chemistry 9(4), 63-75. DOI: 10.4236/ojpchem.2019.94006

Wu, G. F., and Xu, M. (2014). "Effects of boron compounds on the mechanical and fire properties of wood-chitosan and high-density polyethylene composites," BioResources 9(3), 4173-4193. DOI: 10.15376/biores.9.3.4173-4193 
Yildirim, M., Negawo, T. A., Kilic, A., and Candan, Z. (2020). "Developing and characterization of hybrid composites from sustainable green materials," Green Materials (Pre-print). DOI: 10.1680/jgrma.20.00044

Zhang, H., Zhang, J., Song, S., Wu, G., and Pu, J. (2011). "Modified nanocrystalline cellulose from two kinds of modifiers used for improving formaldehyde emission and bonding strength of urea-formaldehyde resin adhesive," BioResources 6(4), 44304438. DOI: $10.15376 /$ biores.6.4.4430-4438

Article submitted: October 31, 2020; Peer review completed: January 2, 2021; Revised version received and accepted: January 17, 2021; Published: January 26, 2021.

DOI: $10.15376 /$ biores.16.1.1875-1890 